\title{
CSF Hydrothorax as a Late Complication of Ventriculoatrial Shunt Catheter Displacement
}

\author{
Ertuğrul Çakır ${ }^{1}$, Erhan Arslan ${ }^{2}$ \\ ${ }^{1}$ Department of Neurosurgery, Karadeniz Teknik University Faculty of Medicine, Trabzon, Turkey \\ ${ }^{2}$ Department of Neurosurgery, Giresun University Faculty of Medicine, Giresun, Turkey
}

A 21-year-old man was admitted to our emergency department with chest pain and progressively increasing dyspnoea commencing 1 week previously. His self-history revealed that he had received a ventriculo-atrial shunt at the age of 2 weeks due to congenital hydrocephalus (Figure 1a). At physical examination, no breathing sounds were heard on the right side. Neurological examination was normal. Total blood counts and $\mathrm{C}$-reactive protein (CRP) were within normal limits. Chest Xray showed right-sided hydrothorax and a catheter tip at the right thoracic apex (Figure 1b). The patient was transferred to the neurosurgery department. A consultation was held with the thoracic department. Thoracentesis was performed 3 times in 1 week, but the hydrothorax still persisted (Figure 1c). Subsequent removal of the ventriculo-atrial shunt catheter with disconnection on the scalp was performed. The distal tip of the catheter was left in the vessel. Symptoms improved rapidly. Chest X-ray revealed resolution of pleural effusion and re-expansion of the right lung (Figure 1d, e). Recovery was uneventful and no further thoracentesis or new shunt catheter were required. The patient was discharged 7 days later in good condition. The patient has remained in good clinical condition at the 2-year follow-up, and hydrocephalus has been arrested.

We suggest that the shunt catheter may migrate from the intravascular space to the thoracic cavity through the area of entry into the internal jugular vein near the brachiocephalic trunk as a result of age-related upward pull. This was suggested by the catheter position in the right thoracic apex. The absence of bleeding into the thoracic cavity while the catheter tip was being exvasated may be attributed to the process having occurred over an extended period. The vessel wall was therefore repaired during this long period. Complications of ventriculoperitoneal or ventriculo-atrial shunts commonly occur due to obstruction, disconnection or infection (1-3).
There are some reports of hydrothorax as a complication of ventriculoperitoneal (V-P) shunting (4). Taub et al. (5) classified V-P shunt thoracic complications into three types: 1) intrathoracic trauma during shunt replacement, 2) peritoneal catheter migration into the thoracic cavity, and 3) pleural effusion with cerebrospinal fluid (CSF) ascites. The peritoneal catheter may migrate into the thoracic cavity in either a supradiaphragmatic or transdiaphragmatic manner. In supradiaphragmatic migration, the peritoneal catheter is accidentally inserted into and out of the pleural cavity during the tunnelling procedure, especially at the supraclavicular fossa, which is the most dangerous area $(6,7)$. In transdiaphragmatic migration, the peritoneal catheter is gradually pulled into the thoracic cavity due to the negative pressure effect of inspiration. Increased intra-abdominal pressure due to peritoneal malabsorption also facilitates this process (5). The peritoneal catheter may migrate from a pre-existing hiatus into the diaphragm or may perforate it. Congenital hiatuses or weak points in the diaphragm are areas where the peritoneal catheter tip may pass into the thoracic cavity. Local inflammation around the peritoneal catheter tip may also facilitate the passage of the shunt tip through the diaphragm $(4,6)$. Hydrothorax may sometimes occur in association with CSF ascites. Peritoneal malabsorption leads to excessive CSF collection in the peritoneal cavity. CSF may pass through the thoracic cavity via congenital hiatuses (foramen Bochdalek or foramen of Morgagni) with increased intraabdominal pressure (6). Ventriculo-pleural shunts have only been used infrequently for hydrocephalus. CSF hydrothorax is also one of the serious thoracic complications of ventriculo-pleural shunts (8). In particular, the long-term results are less satisfactory for ventriculo-pleural shunts, because shunt obstruction or pleural effusions are most frequently

\footnotetext{
Address for Correspondence: Dr. Erhan Arslan, Department of Neurosurgery, Giresun University Faculty of Medicine, Giresun, Turkey Phone: +90 4543101690 e-mail: arserhan@gmail.com

Received: 11.09.2014 Accepted: 02.10.2014 • DOI: 10.5152/balkanmedj.2014.14398

Available at www.balkanmedicaljournal.org 

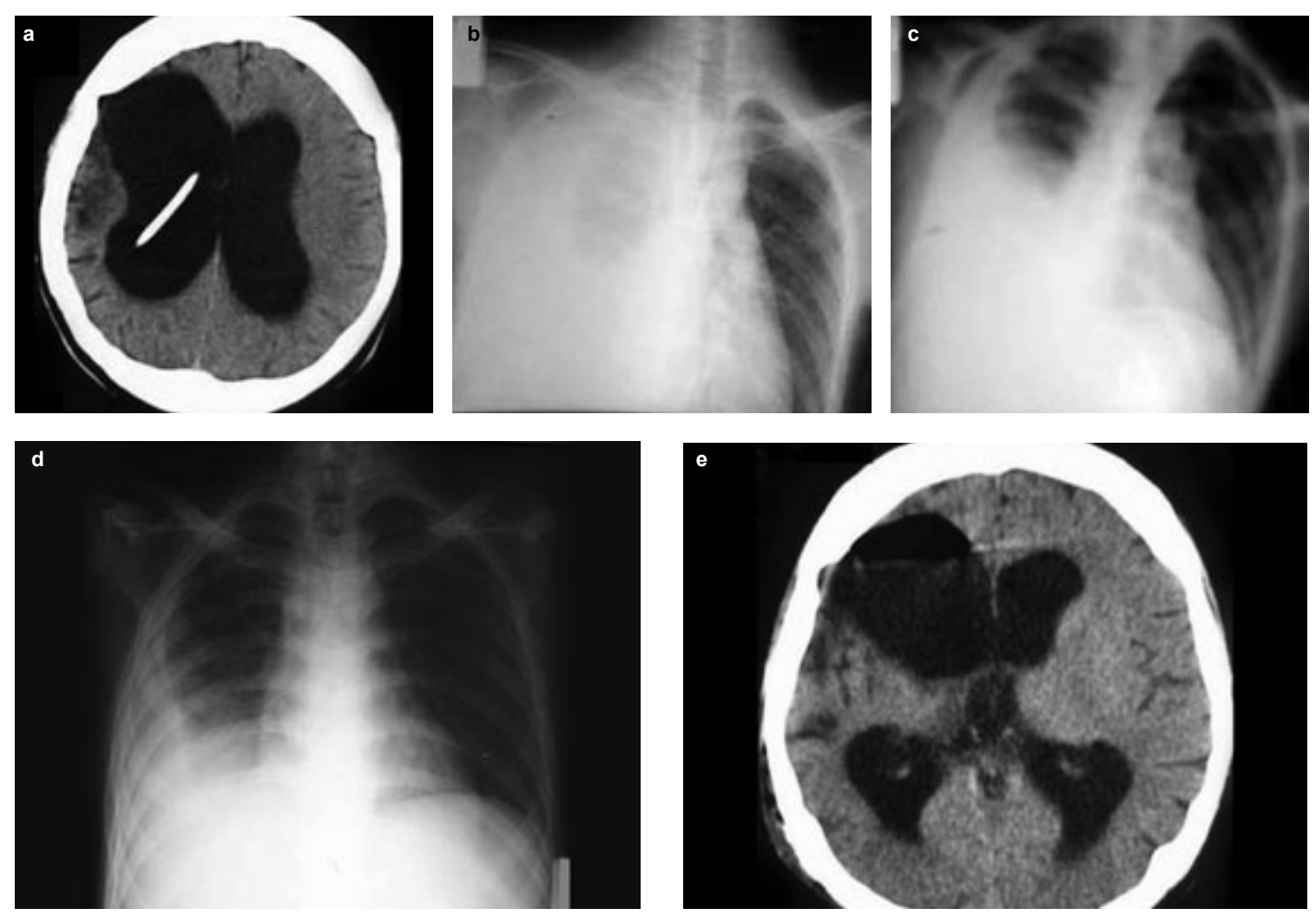

FIG. 1. a-e. The patient's cranial computed tomography (CT) shows the ventricular shunt catheter at the right lateral ventricle (a); Chest $X$-ray shows right sided hydrothorax (b); Chest X-ray after thoracentesis shows persisting hydrothorax (c); Chest X-ray after removal of the ventriculoatrial shunt shows the resolution of pleural effusion and re-expansion of the right lung (d); early postoperative CT of the patient shows a right ventricular pneumocephalus (e).

developed in 3 years (8). The late hydrothorax complicating the ventriculo-pleural shunts can be explained by two hypotheses: (a) Decreased CSF absorption in the pleural space as a result of impaired pleural absorptive capacity secondary to pleural damage due to prior infection and/or chronic exposure to CSF and (b) over-drainage of CSF into the pleural space $(8,9)$. The present case behaved as a ventriculo-pleural shunt due to prolonged drainage of CSF into the pleural space from the right thoracic apex. The possible mechanisms of hydrothorax formation in our patient with ventriculo-atrial shunts are the same as those in ventriculo-pleural shunt.

To the best of our knowledge, this is the first reported case of CSF hydrothorax as a late complication of ventriculo-atrial shunt catheter displacement. We therefore wish to report this unique complication of ventriculo-atrial shunt.

Ethics Committee Approval: N/A.

Informed Consent: Written informed consent was obtained from the patients for the publication of this case report and any accompanying images.

Peer-review: Externally peer-reviewed.
Author contributions: Concept - E.C., E.A.; Design - E.A.; Supervision - E.C.; Resource - E.C., E.A.; Materials - E.A.; Data Collection\&/or Processing - E.A.; Analysis\&/or Interpretation - E.C., E.A.; Literature Search - E.C.; Writing - E.C., E.A.; Critical Reviews - E.A.

Conflict of Interest: No conflict of interest was declared by the authors.

Financial Disclosure: The authors declared that this study has received no financial support.

\section{REFERENCES}

1. Tonn P, Gilsbach JM, Kreitschmann-Andermahr I, Franke A, Blindt R. A rare but life-threatening complication of ventriculo-atrial shunt. Acta Neurochir (Wien) 2005;147:1303-4.[CrossRef]

2. Borgbjerg BM, Gjerris F, Albeck MJ, Hauerberg J, Børgesen SV. A comparison between ventriculo-peritoneal and ventriculo-atrial cerebrospinal fluid shunts in relation to rate of revision and durability. Acta Neurochir (Wien) 1998;140:459-64.[CrossRef]

3. Lam $\mathrm{CH}$, Villemure JG. Comparison between ventriculoatrial and ventriculoperitoneal shunting in the adult population. $\mathrm{Br} J$ Neurosurg 1997;11:43-8.[CrossRef] 
4. Hadzikaric N, Nasser M, Mashani A, Ammar A. CSF hydrothorax--VP shunt complication without displacement of a peritoneal catheter. Childs Nerv Syst 2002;18:179-82.[CrossRef]

5. Taub E, Lavyne MH. Thoracic complications of ventriculoperitoneal shunts: casereport and review of the literature. Neurosurgery 1994;34:181-3.[CrossRef]

6. Ulus A, Kuruoglu E, Ozdemir SM, Yapici O, Sensoy G, Yarar E, et al. CSF hydrothorax: Neither migration of peritoneal catheter into thechest nor ascites. Case report and review of the literature. Childs Nerv Syst 2012;28:1843-8.[CrossRef]
7. Doh JW, Bae HG, Lee KS, Yun IG, Byun BJ. Hydrothorax from intrathoracicmigration of a ventriculoperitoneal shunt catheter. Surg Neurol 1995;43:340-3.[CrossRef]

8. Küpeli E, Yilmaz C, Akçay S. Pleural effusion following ventriculopleural shunt: Case reports and review of the literature. Ann Thorac Med 2010;5:166-70.[CrossRef]

9. Grunberg J, Rébori A, Verocay MC, Ramela V, Alberti R, Cordoba A. Hydrothorax due to ventriculopleural shunting in a child with spina bifida on chronic dialysis: third ventriculostomy as an alternative of cerebrospinal diversion. Int Urol Nephrol 2005;37:571-4.[CrossRef] 